\title{
PROJETOS DE EXTENSÃO COMO DINAMIZADORES DA FORMAÇÃO INICIAL DE PROFESSORES DE INGLÊS
}

Angélica Araújo de Melo MAIA

Universidade Federal da Paraíba

RESUMO: A pesquisa apresentada nesse artigo parte do pressuposto de que projetos de extensão em cursos de Licenciatura podem não só fortalecer a dimensão política e de comprometimento social do trabalho docente, mas também expandir os campos de atuação dos professores em formação envolvidos para além do contexto das salas de aula do ensino regular, de forma a promover um desenvolvimento profissional sensível a contextos diversificados e às necessidades de diferentes públicos. Dessa maneira, apresentamos uma experiência de um projeto de extensão vinculado ao curso Letras-Inglês, vivenciada no decorrer do ano de 2015 na Universidade Federal da Paraíba. O projeto teve como público-alvo jovens de uma organização não governamental da cidade de João Pessoa e permitiu que os professores participantes ministrassem aulas de língua inglesa que buscavam integrar a perspectiva de Inglês para Fins Específicos (DUDLEY-EVANS, ST JOHN, 2005) e o Letramento Crítico (JORDÃO, 2013). Discutiremos, através da análise das reflexões elaboradas pelos bolsistas sobre as aulas ministradas, os conhecimentos que puderam ser construídos no trabalho com o público de jovens da ONG, os problemas de ordem prática que se apresentaram para o trabalho com as duas perspectivas metodológicas propostas (ESP e Letramento Crítico) e as estratégias que foram adotadas pelos professores em formação para atingir os objetivos almejados e engajar os alunos no processo de ensino-aprendizagem. A análise foi orientada pelas categorias de capacidades de linguagem docente (capacidade de ação docente, capacidade discursiva docente e capacidades linguístico-discursiva docente) (QUEVEDOCAMARGO, 2015). Entendemos que a reflexão sobre as capacidades docentes trabalhadas no projeto poderá resultar em uma expansão de perspectiva no que se refere à agência docente (capacidade de autogestão profissional) e à ampliação dos saberes trabalhados nos currículos de formação inicial de professores de línguas estrangeiras.

PALAVRAS-CHAVE: Projeto de extensão; letramento crítico; capacidades de linguagem docente

ABSTRACT: The research presented in this paper assumes that extension projects in teacher education courses might not only strengthen the political dimension and the social commitment of the teaching job, but also expand the fields of expertise of the teachers-to-be involved in that kind of project beyond the context of regular school classrooms, in order to promote a professional development process which is sensitive to varied contexts and to the needs of different audiences. In this way, we present an extension project experience which took place in the scope of the English teacher education course of Universidade Federal da Paraiba along the year of 2015. The project targeted a group of young people from a non-governmental organization of the city of João Pessoa and provided the teachers-to-be involved the opportunity to teach lessons that sought to integrate the perspective of English for Specific Purposes (DUDLEY-EVANS, ST JOHN, 2005) and Critical Literacy (JORDÃO, 2013). By looking into the 
reflections produced by the teachers-to-be about the lessons taught, we analyze the knowledge that could be built through the work with the youth at the non-governmental organization, the practical problems that had to be faced while trying to integrate the two proposed methodological approaches (ESP and critical literacy) and the strategies that were adopted by the teachers-to-be to achieve the desired goals and to engage students in the teaching-learning process. The analysis was guided by the categories of teaching language capacities (action teaching capacities, discursive teaching capacities and linguistic-discursive teaching capacities) (QUEVEDO-CAMARGO, 2015). We understand that the reflection about the teaching capacities developed through the project might result in an expansion of perspective regarding teaching agency (self-management capacity) and lead to an extension of the knowledge proposed in the curricula of language teacher education courses.

KEYWORDS: Extension projects; critical literacy; teaching language capacities

\section{Introdução}

A extensão universitária é parte essencial na constituição do papel social das universidades (JEZINE, 2004; MARTINS, 2008). Aliada ao ensino e à pesquisa, ela pode oportunizar a formação de profissionais sensíveis às demandas da sociedade, sobretudo dos grupos mais vulneráveis e empobrecidos.

Em relação à formação docente, os projetos de extensão universitária se configuram como espaços de desenvolvimento profissional capazes de promover a articulação teoria/prática (contemplando a indissociabilidade entre ensino, pesquisa e extensão), que é tão valorizada no discurso dos documentos oficiais de formação de professores, tais como as Diretrizes Curriculares Nacionais para a Formação de Professores da Educação Básica (BRASIL, 2002; BRASIL, 2015).

Além disso, a participação do professor em formação em projetos de extensão tem o potencial de viabilizar a construção de uma identidade docente sensível a "questões e problemas socioculturais e educacionais, com postura investigativa, integrativa e propositiva em face de realidades complexas, a fim de contribuir para a superação de exclusões sociais [...]" (BRASIL, 2015, artigo $8^{\circ}$, parágrafo VII). Nesse sentido, concordamos com Jezine (2004, [ s.p.]), quando defende que atualmente a extensão se constitui "parte integrante da dinâmica pedagógica curricular do processo de formação e produção do conhecimento, envolvendo professores e alunos de forma dialógica, promovendo a alteração da estrutura rígida dos cursos para uma flexibilidade curricular que possibilite a formação crítica". Entendemos que a extensão se apresenta como um importante instrumento de flexibilização curricular nos cursos de licenciatura, oferecendo aos extensionistas/ futuros professores vivências de práticas de docência relevantes do ponto de vista social, cultural, ético e afetivo.

Valorizar o papel da extensão na formação inicial de professores implica na necessidade de se compartilhar experiências concretas desenvolvidas nesse campo, de forma a fazer reverberar os aspectos positivos dessas vivências, bem como discutir os tipos de saberes que elas possibilitam construir. Assim, esse artigo visa socializar as contribuições oportunizadas por um 
projeto de extensão na área de formação de professores de língua inglesa, implementado no âmbito do PROBEX da Universidade Federal da Paraíba no ano de 2015.

O objetivo central do trabalho é discutir o processo de formação docente inicial para o ensino de língua inglesa, a partir do contexto do projeto de extensão - PROBEX, elencando e analisando as capacidades construídas pelos professores em formação, em diálogo com algumas teorias que serviram de base às ações formativas desenvolvidas, quais sejam: os saberes docentes (TARDIF, 2000); e as capacidades de linguagem docente (DOLZ; PASQUIER; BRONCKART, 1993; QUEVEDO-CAMARGO, 2013;2015).

Serão analisados alguns fragmentos dos relatos reflexivos sobre as oficinas ministradas pelos professores participantes, de forma a exemplificar os aspectos da formação dinamizados pelo projeto. Trata-se de uma pesquisa exploratória de caráter interpretativista que se propõe a mapear os temas em destaque nos textos analisados e associá-los às múltiplas dimensões discutidas na parte teórica do trabalho.

Em primeiro lugar, situaremos o projeto de extensão em discussão, descrevendo seus espaços, atores, objetivos e procedimentos. Em seguida, discutiremos as categorias teóricas acima elencadas, para então proceder à análise dos fragmentos destacados, de forma a compreender como a experiência da extensão tornou possível um processo de formação docente diferenciado para os dois professores envolvidos.

\section{O projeto: objetivos, espaços, atores e ações}

O projeto de extensão Inglês para adolescentes e jovens: uma ferramenta para a profissionalização e o letramento crítico teve o objetivo de oferecer oficinas de língua inglesa para adolescente e jovens em situação de vulnerabilidade social de uma organização não governamental da cidade de João Pessoa, Paraíba, de forma a instrumentalizá-los para a inserção no mercado de trabalho no ramo de turismo e hotelaria, promovendo a inclusão social, e ao mesmo tempo, possibilitar o acesso dos participantes a textos sobre temas relevantes na atualidade, suscitando debates, posicionamentos e o desenvolvimento do senso crítico.

Para isso, foram realizadas oficinas semanais de duas horas de duração na sede da ONG, situada em uma comunidade de baixo nível socioeconômico da cidade de João Pessoa. Essa instituição tem como missão a efetivação dos direitos das crianças e adolescentes em situação de vulnerabilidade social; daí o compromisso do projeto com a construção da cidadania através da abordagem de temas de relevância social.

Contamos com a participação de cerca de 10 alunos, que frequentaram as oficinas oferecidas entre março e novembro de 2015. As aulas foram ministradas por dois bolsistas de extensão, que eram professores em formação inicial, alunos do curso de Letras Inglês da Universidade Federal da Paraíba (MAIA, DOURADO, FERREIRA, CONCEIÇÃO, 2016). Um dos bolsistas tinha pouca experiência como professor anteriormente ao projeto, enquanto o ou tro bolsista já tinha considerável experiência como professor de inglês de uma escola de línguas. 
As oficinas do projeto foram planejadas aliando os princípios de duas abordagens teóricometodológicas: a perspectiva do Inglês para Fins Específicos (ESP) (HUTCHINSON; WATERS, 1987; DUDLEY-EVANS; ST JOHN, 2005) e a abordagem do letramento crítico (ROJO, 2009), aplicada ao ensino de língua estrangeira (JORDÃO, 2013; MATTOS, 2014; DUBOC, 2015). Assim, enquanto a primeira parte das aulas, que tinham duração de aproximadamente 2 horas no total, era destinada ao desenvolvimento de práticas de linguagem relacionadas a situações do mundo do trabalho de turismo e hotelaria, no segundo momento, as atividades buscavam promover a discussão de temas pertinentes e relevantes no mundo atual, como o consumismo, as relações humanas, o trabalho infantil e a redução da maioridade penal. Esses temas foram trabalhados através de gêneros textuais do interesse dos participantes, como música, vídeos e imagens, além de notícias e peças de propaganda contemporâneas. É importante ressaltar que nenhum dos professores em formação havia trabalhado antes em uma organização governamental, e nem ministrado cursos que aliassem a perspectiva do Inglês para Fins Específicos com o ensino de línguas voltado para o Letramento Crítico.

Foram ministradas um total de 46 horas de aula, sendo que 32 horas foram conduzidas pelo professor em formação 1 (o mais experiente) ao longo de todo o projeto e distribuídas em 2 blocos de 8 oficinas cada, e as outras 14 horas foram ministradas pelo professor em formação 2 (o menos experiente) a uma nova turma de participantes que se formou no segundo semestre do ano. Os planos de aula eram elaborados pelos bolsistas a cada semana, discutidos com a professora formadora coordenadora do projeto e reformulados, se fosse necessário. Os professores em formação ainda escreviam um diário reflexivo sobre cada oficina ministrada, que era lido e comentado pela professora formadora e devolvido ao bolsista para reflexão.

Em relação à proposta de formação docente colocada em prática ao longo do projeto, ela se pautou por uma epistemologia da prática docente centrada na investigação reflexiva (SCHÖN, 1983). Sendo assim, o projeto procurou oferecer aos professores um processo formativo que abrisse espaço à ampliação dos conhecimentos relacionados ao "saber fazer", sempre de forma situada e levando em conta aquilo que a situação de aprendizagem demandava em termos de construção de conhecimentos da língua inglesa e de procedimentos metodológicos e interações apropriados para o público-alvo em questão. Além disso, incentivou-se os professores a adotar a postura de refletir na ação e sobre a ação (SCHÖN, 1983).

Tendo apresentado um breve relato do contexto de desenvolvimento do projeto, na próxima seção, discutiremos alguns dos pressupostos teóricos que servirão de referência na análise das capacidades docentes ampliadas a partir da experiência proporcionada aos professores participantes no âmbito do projeto em questão.

\section{Saberes e capacidades de linguagem docente: referenciais para a compreensão do processo de formação inicial}

Começaremos a discussão teórica desse trabalho a partir da noção de saberes docentes proposta por Tardif (2000). Em seguida, tentaremos estabelecer uma relação entre esses saberes e as capacidades de linguagem docente sugeridas por Quevedo Camargo (2015), com base nas teorizações sobre capacidades de linguagem de pesquisadores do Interacionismo Sociodiscursivo (ISD) (DOLZ; PASQUIER; BRONCKART, 1993). Essa escolha se justifica não só pelo meu 
lugar como pesquisadora, uma vez que na Universidade da qual faço parte, a pesquisa no âmbito da Linguística Aplicada sobre formação docente tem sido desenvolvida em grande parte com base no Interacionismo Sociodiscursivo, destacando-se nessa área (entre muitos outros) os trabalhos de Medrado e Pérez (2011), Reichmann (2014), Freudenberger (2015); como também porque julgo que esse referencial teórico pode abrir grandes possibilidades no que tange à interpretação dos saberes construídos por professores em formação inicial em projetos de extensão.

Considerando o conceito de saberes docentes, Tardif, em suas pesquisas, distancia esse conceito da lógica da racionalidade técnica, que entendia que o processo de formação do professor deveria focar no domínio de conhecimentos, estratégias e técnicas de ensino para aplicação nos contextos pedagógicos, o que, por si só, garantiria uma prática de ensino "eficaz" nos diferentes espaços de aprendizagem. Nesse sentido, o autor contrapõe os saberes docentes a essa lógica racional e muitas vezes distante do que de fato acontece em sala de aula, e valoriza um percurso formativo do professor que tem por base a epistemologia da prática, ou seja, "o estudo do conjunto dos saberes utilizados realmente pelos profissionais em seu espaço de trabalho cotidiano para desempenhar todas as suas tarefas" (TARDIF, 2000, p.10).

Ora, uma das características apontadas por Tardif ao tentar definir a natureza desses saberes é o fato de que eles são personalizados e situados ${ }^{1}$. Isso quer dizer que não se trata de um rol de conhecimentos e formas de agir que possam ser aplicadas a qualquer contexto de atuação profissional de maneira universal e generalizante e/ou que possam ser reproduzidos ou copiados de uma profissional para a outro sem a devida reflexão e redimensionamento, pois cada prática pedagógica deve ser pensada de maneira a dar conta dos objetivos definidos para cada situação específica de ensino-aprendizagem. Nesse ponto, a visão de saberes docentes pode ser articulada ao construto de capacidades de linguagem docente, desenvolvido por Quevedo-Camargo (2015), dentro do referencial teórico do Interacionismo Sociodiscursivo (ISD).

Na perspectiva do ISD, o desenvolvimento humano está centralmente relacionado a ações de linguagem de caráter coletivo e interacional e que são sócio-historicamente situadas (BRONCKART, 1999/2009). Essas ações ou práticas de linguagem se concretizam através de textos orais ou escritos, o que levou teóricos dessa perspectiva a procurar definir um construto que pudesse dar conta das diferentes capacidades de linguagem a serem mobilizadas para que um texto seja articulado dentro de cada situação específica de interação. Essas capacidades corresponderiam a "aptidões solicitadas para a realização de um texto dentro de uma situação de interação determinada” (DOLZ; PASQUIER; BRONCKART, 1993, p.30, minha tradução). Elas compreendem as capacidades de ação, as capacidades discursivas e as capacidades linguísticodiscursivas.

As capacidades de ação apontam para a necessidade de que a produção linguageira se adeque às características do contexto e do referente a quem ela se dirige; as capacidades discursivas contemplam as escolhas a serem feitas (entre os diferentes modelos discursivos disponíveis) dos tipos de discurso que facilitem a concretização da ação linguageira. Por último,

\footnotetext{
1 Para Tardif (2000), além de serem personalizados e situados, os saberes docentes são temporais, plurais e heterogêneos. Optamos por destacar os aspectos da personalização e contextualizações por serem os que pretendemos relacionar ao construto de capacidades de linguagem docente do ISD.
} 
as capacidades linguístico-discursivas englobam o domínio das operações psicolinguísticas necessárias para a construção de cada discurso específico. Na arquitetura textual do ISD, essas operações se dividem em cinco conjuntos: "as operações de planificação, de estruturação temporal, de coesão, de conexão e de modalização" (Ibid., p.31, minha tradução).

Mais recentemente, esse construto foi retomado e relacionado à formação docente, visando estabelecer um quadro teórico-epistemológico para especificar que elementos poderiam compor a base da formação de professores de línguas na atualidade. Assim, os três tipos de capacidades acima mencionados são relidos à luz das especificidades do contexto de formação de professores, sendo denominados de capacidades de linguagem docente, definidas como "um conjunto de operações dentro do âmbito da formação e atuação do docente de LI que permitem a realização de ações de linguagem e funcionam como um instrumento para mobilizar os conhecimentos docentes e operacionalizar a aprendizagem para a docência de LI" (QUEVEDOCAMARGO, 2015, p.42-43).

São discutidos quatro grandes tipos de capacidades de linguagem docente: a capacidade de ação docente, a capacidade discursiva docente, a capacidade linguístico-discursiva e a capacidade de autogestão profissional.

A capacidade de ação docente envolveria "os aspectos relativos ao contexto físico e sociossubjetivo da atuação do professor” (Ibid., p. 46) e abrange os conhecimentos formais referentes ao contexto de trabalho, como por exemplo, o domínio das políticas educacionais vigentes ou o conhecimento sobre os tipos de alunos que podem ser encontrados em uma escola pública e suas necessidades. Por outro lado, essa capacidade também engloba os saberes que dizem respeito ao ato de ensinar, tais como: teoria de ensino e aprendizagem, materiais e recursos, métodos e técnicas de ensino de LE, entre outros componentes.

A capacidade discursiva docente está intimamente vinculada à prática de docência, pois ela possibilita que o futuro professor aprenda a mobilizar todos os dados, informações e saberes que construiu ao longo da formação e da vida para responder às demandas de cada contexto físico e sociossubjetivo de ensino (QUEVEDO - CAMARGO, 2015). Sendo assim, entendemos que essa capacidade é de ordem processual e requer do professor uma constante relação com as variáveis do seu contexto, em um movimento de avaliação que nunca se encerra e que permite selecionar conteúdos, planejar situações de aprendizagem, recursos didáticos e matérias de ensino, tendo sempre como parâmetro a observação da condições de aprendizagem concretas que ele encontra na sala de aula de LI onde o processo de ensino-aprendizagem se desenvolve e as características dos alunos participantes. No escopo dessa pesquisa, essa capacidade será a mais mobilizada, uma vez que procuraremos evidenciar o desenvolvimento dos professores em formação a partir de sua inserção em um contexto de atuação concreto, que foi o projeto de extensão.

No que se refere à capacidade linguístico-discursiva, ela contempla os conhecimentos sobre o objeto de ensino, ou seja, a língua inglesa, em todas as suas dimensões: práticas de compreensão e produção oral e escrita, morfologia, sintaxe, semântica, literatura, dentre outras. Incluído nessa capacidade está também o uso da língua inglesa para fins didáticos em sala de aula (QUEVEDO - CAMARGO, 2015) 
A capacidade de autogestão profissional é sugerida pela autora para representar "o posicionamento do (futuro) docente de LI diante da sua profissão, da sua atuação sobre seu processo de profissionalização e desenvolvimento do profissionalismo" (Ibid., p. 57). É considerada uma capacidade basilar, pois é ela que faz com que as demais capacidades sejam acionadas e se desenvolvam.

A imagem de uma engrenagem é sugerida por Quevedo-Camargo para exemplificar a inter-relação entre as quatro capacidades descritas acima no processo de formação profissional. Elas perpassam umas pelas outras de forma imbricada, podendo tanto dinamizar o processo global de formação - se funcionarem de forma integrada e mutuamente responsável, como também travar o processo formativo (caso uma delas seja negligenciada ou não esteja em harmonia com os princípios epistemológicos das outras capacidades).

Similarmente, consideramos a imagem de um dínamo como significativa para representar a transformação dos saberes, das capacidades e da identidade docente que julgamos ter ocorrido para os professores participantes dentro do projeto de extensão que analisamos. Ao transformar energia mecânica em energia elétrica, o dínamo produz movimento e renovação. Relacionando esse processo à formação docente, verificamos que a inserção do professor em formação no projeto de extensão pode conduzir a um movimento de transformação e à constituição de algo novo, que poderá ter um impacto diferenciado nas práticas de ensino e na aprendizagem de LI.

\section{O movimento de formação inicial para a docência em LI dentro do PROBEX: um olhar sobre as capacidades de linguagem docentes desenvolvidas}

Para organizar a apresentação dos dados, optamos por identificar os fragmentos que pudessem ser relacionados ao desenvolvimento de alguma das capacidades de linguagem docente, para em seguida discuti-los e relacioná-los ao tipo de capacidade com a qual avaliamos que eles mais fortemente se relacionam. Os fragmentos serão identificados pelas siglas: RR relato reflexivo; PF1 - professor em formação 1 e PF2 - professor em formação 2 (conforme perfil apresentado na primeira seção desse trabalho). Como os professores em formação escreveram seus relatos em inglês, os fragmentos desses participantes foram traduzidos pela autora.

Um dos objetivos do projeto de extensão Inglês para adolescentes e jovens: uma ferramenta para a profissionalização e o letramento crítico foi oferecer a licenciandos do curso Letras-Inglês da UFPB a oportunidade de ministrar aulas em um contexto real de ensino do idioma, bem como de aprender, a partir dessa experiência, a fazer a relação teoria/prática, construindo sua identidade de professor de forma reflexiva.

Esse objetivo evidencia que o projeto partiu de princípios teóricos e metodológicos específicos, sobre os quais os professores em formação deveriam ter alguma noção para conseguir planejar aulas que cumprissem os objetivos de aprendizagem traçados.

Nesse sentido, como já mencionado anteriormente, o projeto partiu da perspectiva do Inglês para Fins Específicos (ESP) (HUTCHINSON; WATERS, 1987; DUDLEY-EVANS; ST JOHN, 2005) e da abordagem do letramento crítico (ROJO, 2009), aplicada ao ensino de língua 
estrangeira (JORDÃO, 2013; MATTOS, 2014; DUBOC, 2015) para orientar o planejamento das aulas.

No tocante à perspectiva do Inglês para Fins Específicos, o projeto procurou desenvolver nas oficinas atividades relacionadas aos três aspectos mencionados por Hutchinson e Waters (1987) e que nos parecem fundamentais, considerando o objetivo de instrumentalizá-los para o mercado de trabalho do ramo do turismo e hotelaria: as necessidades dos alunos (aquilo que eles precisam aprender para se inserir no mercado de trabalho), as lacunas desses alunos (que considera aquilo que eles já sabem e aquilo que eles ainda precisam aprender) e os desejos dos alunos (aquilo que os motivaria a aprender mais efetivamente a língua inglesa).

O fato de o projeto se desenvolver em uma instituição cuja missão é promover os direitos das crianças e adolescentes sugeriu a adoção de uma abordagem de ensino orientada para uma educação linguística que ao mesmo tempo contribuísse para a formação de sujeitos capazes de entender os sentidos que circulam ao seu redor de forma crítica e que, guiados por esse entendimento, fossem capazes de agir discursivamente no mundo em busca de mudanças, sejam elas pessoais ou mudanças nas suas comunidades. Assim, o letramento crítico foi adotado como parâmetro de ação e norteou o trabalho com temas de relevância social e que pudessem fomentar a reflexão e a criticidade nos alunos (ROJO, 2009; JORDÃO, 2013; MATTOS, 2014; DUBOC, 2015).

A princípio, essas perspectivas teórico-metodológicas foram adotadas em momentos específicos nas aulas que não se relacionavam. Para começar cada oficina, eram planejadas atividades orais e escritas referentes aos usos da língua inglesa em ambientes de trabalho do campo do turismo e hotelaria. Em um segundo momento, era trabalhado um texto em língua inglesa sobre temas como combate ao trabalho infantil, abuso e exploração sexual (dentre outros), cujas ideias serviam como ponto de partida para as discussões (geralmente em língua materna) voltadas para o letramento crítico dos participantes. Pouco a pouco, houve um movimento no sentido de procurar integrar essas duas perspectivas nas oficinas. Esse foi um dos grandes momentos de desconforto para os professores em formação, que parece ter provocado o desenvolvimento tanto da capacidade de ação como da capacidade discursiva docente, o que se evidencia nos fragmentos abaixo:

Os alunos pareciam engajados na maior parte da aula e, com exceção de dois deles ( $\mathrm{J}$ and $\mathrm{L}$ ), todos contribuíram muito para a discussão sobre trabalho infantil. Os recursos visuais utilizados foram muito apropriados e facilitaram a compreensão dos alunos sobre o tópico. Aparentemente, a transição do momento do letramento crítico para o momento do Inglês para fins específicos se deu suavemente e os alunos usaram a língua alvo planejada, fazendo a relação com $o$ tópico do letramento crítico (RR, PF1, julho 2015, grifo nosso, tradução nossa).

Bem, na parte do Inglês para fins específicos, tudo aconteceu como planejado. Entretanto, na parte do letramento crítico, eu nunca esperava que eles fossem tão maduros para compartilhar o que eles disseram. Eu digo isso porque eu acho que alguns assuntos que eles compartilharam são muito pessoais. Eu me sinto bem por eles se sentirem confortáveis o bastante para compartilhar esses assuntos tão pessoais conosco (RR, PF2, agosto 2015, tradução nossa). 
Do ponto de vista da capacidade de ação docente, o primeiro fragmento remete ao domínio de conhecimentos voltados para o planejamento da aula, de forma a trabalhar com sucesso elementos específicos da língua alvo, como também evidencia um embasamento teórico para distinguir entre os usos da linguagem para fins específicos e os usos da linguagem para promover a reflexão e criticidade, ou seja, saber distinguir entre práticas de linguagem de diferentes esferas de atividade.

No entanto, como já explicamos anteriormente, é a capacidade discursiva docente, que parece ser a mais "dinamizada" pela experiência de extensão. Essa capacidade é a que mais especificamente pode ser articulada à afirmação de Tardif (2000) de que os saberes docentes são personalizados e situados. Nos fragmentos destacados, encontramos alguns exemplos de desenvolvimento dessa capacidade. Um deles é o fato de PF 1 mencionar a sua sensibilidade aos padrões de engajamento e de participação dos alunos ao longo da aula, bem como o movimento de PF2 ao avaliar o nível de confiança e conforto dos alunos em relação ao professor, ao compartilharem "assuntos pessoais" na discussão realizada no momento do letramento crítico. Esse são tipos de saberes que não podem ser aprendidos em nenhum livro, mas que podem ser experienciados ou sentidos em situações concretas de docência, a partir do momento em que o professor em formação começa a olhar reflexivamente para suas práticas e interage com seu contexto de atuação. No quadro analítico proposto por Quevedo-Camargo (2015) para a capacidade discursiva docente, esses conhecimentos se encaixariam no item avaliação, na medida em que demonstram habilidades de "avaliar o progresso do aluno" e utilizar essa avaliação para "informar e redirecionar o trabalho em classe" (p.53). No que se refere ao item materiais e recursos, PF1 comenta o fato de ter percebido que os recursos visuais selecionados foram apropriados para se alcançar um dos objetivos da aula que era facilitar a compreensão dos alunos sobre o tópico. Ao fazer esse comentário, ele parece ter aprendido tanto sobre as escolhas adequadas à situação de ensino como sobre a necessidade de variação dos materiais, de forma a favorecer alunos com diferentes estilos de aprendizagem.

Um segundo bloco de fragmentos traz à tona aspectos da capacidade discursiva docente relacionados ao planejamento das aulas (oficinas) em contraponto ao que foi efetivamente realizado, segundo a ótica do professor em formação:

Foi bem claro perceber a ligação entre as duas partes da aula (Inglês para Fins Específicos e Letramento Crítico). Durante a parte de Inglês para Fins Específicos, os alunos captaram o sentido, a estrutura e a pronúncia do presente contínuo. Também foi interessante ver que eles tinham adquirido muito mais itens da língua do que o professor tinha preparado. Havia uma lista de 10 verbos na atividade (RR, PF 1, julho 2015, grifo nosso, tradução nossa).

O tempo que eles levaram para entender os exemplos, eu pensei que eles iriam entender meus exemplos, mas no fim, eu vi que eu precisava ser mais claro, e eu me senti um pouco perdido, quando eu vi que eles não estavam entendendo o que eu estava explicando (RR, PF2, junho 2015, grifo nosso, tradução nossa). 
$\mathrm{Na}$ primeira passagem, PF1 se refere a capacidades linguístico-discursivas que ele conseguiu trabalhar com sucesso com os alunos (sentido, estrutura e pronúncia do presente contínuo). Isso sugere que o próprio professor se sentia seguro em termos de conhecimentos linguísticos para trabalhar esse tempo verbal com os alunos, ou seja, ele revela uma capacidade linguístico-discursiva docente satisfatória para aquele contexto de ensino.

No que tange à capacidade discursiva docente, PF1 é capaz de avaliar que os objetivos traçados para aula foram não só alcançados como superados. Houve um aprendizado do professor ao escolher ir além do que estava previsto no plano e receber uma resposta positiva dos alunos em termos de aprendizagem.

No mesmo campo da capacidade discursiva docente, observa-se uma experiência de menor assertividade por parte de PF2, quando ele percebe (no segundo fragmento) que os exemplos que tinha planejado utilizar na aula não estavam servindo para facilitar a compreensão dos alunos. Nesse momento, o professor se reconhece "perdido", e menciona que o tempo da aula utilizado pelos alunos naquela atividade foi longo demais pela sua falta de capacidade de escolher os procedimentos metodológicos mais adequados às necessidades dos alunos ali presentes. Entendemos que uma experiência dessa natureza pode ser um importante instrumento de desenvolvimento profissional para o professor em formação, que tem a oportunidade de refazer as suas escolhas de forma mais consciente em situações futuras de ensino.

Outro bloco de excertos dos relatórios traz à tona a capacidade de autogestão profissional (ou agência docente), que se manifesta quando o professor se mostra capaz de identificar aspectos de sua prática que precisa aperfeiçoar e de colocar em prática estratégias para transformar esses aspectos. Vejamos os entrechos abaixo:

Eu tenho que trabalhar no planejamento, sequenciando a aula e dividindo a prática para que pontos diferentes sejam abordados (língua alvo), mas acima de tudo, dar oportunidade aos alunos de usar a língua alvo antes de prosseguir para a próxima [etapa] (RR, PF1, Julho 2015, tradução nossa).

Eu usei mais a linguagem corporal para tornar os assuntos mais claros para os alunos, e me pareceu que isso funcionou, porque eu percebi os alunos interagindo mais rapidamente e respondendo a comandos simples mais rápido do que o habitual. Além disso, eu percebi que eles foram capazes de entender melhor (RR, PF2, setembro 2015, tradução nossa).

Na primeira passagem, PF1 especifica alguns elementos de sua prática que necessitam ser trabalhados, tais como o sequenciamento e a variação dos pontos abordados, bem como a criação de oportunidades para que os alunos possam praticar ou usar as partes da língua a que foram apresentados antes de partir para algo novo. A capacidade de refletir sobre as ações empreendidas e de identificar o que parece ser mais relevante em termos de atividade pedagógica para os alunos colocam em evidência o espaço da extensão como um laboratório, onde é possível construir conhecimentos através da observação e da tentativa e erro. 
Quanto ao fragmento de PF2, é interessante observar a transformação gerada em relação ao fragmento anterior em que o professor se mostra perdido diante da dificuldade dos alunos de compreender os exemplos dados em língua inglesa. Dessa vez, esse professor se refere a uma escolha pedagógica de usar a linguagem corporal para dar instruções, seguida da avaliação positiva da ação docente, que se reflete no fato de os alunos demonstrarem um melhor desempenho em relação à interação com o professor e entre eles.

Por fim, destacamos um fragmento de PF1 que aponta para uma postura de maior conforto no que se refere à quantidade e frequência do uso da língua alvo em sala de aula e na percepção do engajamento discursivo dos alunos, tanto em termos de compreensão como de produção:

Tendo começado a parte do Letramento Crítico, o professor sentiu que os alunos já estavam preparados para ter a maior parte da aula na língua alvo, uma vez que a linguagem [necessária] foi ensinada de antemão e os alunos não iriam ter dificuldade em entender. De fato, eles foram capazes de acompanhar e comentar quando o professorar elicitou as respostas, tudo na língua alvo" (RR, PF1, junho 2015, tradução nossa).

Através da opção de ensinar antecipadamente o vocabulário necessário aos alunos para expressarem suas ideias sobre o tema abordado de forma básica, o professor revela que conseguiu tornar o uso da língua inglesa mais eficiente na aula, uma vez que os alunos conseguiram acompanhar as discussões feitas nessa língua, e ainda expressar algumas ideias utilizando o inglês. Destaca-se, nesse exemplo, a ampliação da capacidade de ação docente e da capacidade discursiva docente do professor, ao obter sucesso na adoção de estratégias metodológicas facilitadoras da interação e ao avaliar o impacto da adoção dessas estratégias na aprendizagem dos alunos.

\section{Alguns comentários finais}

Ao longo desse trabalho, discutimos sobre as possibilidades formativas proporcionadas a professores em formação inicial dentro de um projeto de extensão, focando nos saberes situados e nas capacidades de linguagem docentes que puderam ser construídas e percebidas através da análise de fragmentos dos relatos dos extensionistas e professores em formação participantes da pesquisa.

Entre os aspectos destacados na análise, foram evidenciados elementos relacionados sobretudo à capacidade discursiva docente. Avaliamos que isso ocorreu pela especificidade do projeto de extensão que permitiu aos professores planejar, ministrar aulas, e ao mesmo tempo refletir sobre as práticas de docência e transformá-las ao longo do tempo, de forma a atender às necessidades e desejos dos alunos. Assim é que os fragmentos destacados e analisados acima indicam que os professores parecem ter ampliado as possibilidades de ação pedagógica, com destaque para os itens abaixo: 
- Capacidade de ação docente: planejar aulas; aplicar os princípios do Inglês para Fins Específicos e do Letramento Crítico; elaborar materiais didáticos para essas duas abordagens.

- Capacidade discursiva docente: fazer escolhas sobre sequenciamento do conteúdo de forma a facilitar progresso dos alunos na língua; avaliar o nível de compreensão dos alunos e o uso que eles fazem da língua e balancear o uso da língua materna e da língua inglesa, tendo como horizonte o desenvolvimento linguístico e a formação crítica dos alunos; avaliar as escolhas pedagógicas bem-sucedidas e as que não funcionaram e pensar em práticas alternativas.

- Capacidade linguístico-discursiva docente: usar as estruturas da língua alvo de forma adequada e explicar sobre o uso de certos componentes aos alunos; adequar o uso da língua inglesa e da língua materna, fazendo escolhas linguísticas (de caráter verbal e não verbal), visando a engajar os alunos nas aulas, através de explicações e instruções claras;

- Capacidade de autogestão profissional: tomar decisões em sala de aula; refletir sobre a própria prática, avaliar as próprias ações, reconhecer os insucessos, buscar alternativas para fazer diferente e reavaliar permanentemente as práticas em sala de aula e o próprio percurso formativo.

Ressaltamos que a formação docente entendida como uma prática social é multidimensional; e que as capacidades de linguagem docente aparecem de forma integrada. Acreditamos que devem ser valorizadas as experiências de formação que contemplem todas as dimensões da linguagem/ação da forma mais abrangente possível.

Nesse sentido, defendemos que a extensão se apresenta como um desses espaços privilegiados de formação, desde que, conforme se pode verificar através da pesquisa aqui apresentada, todas as dimensões da linguagem docente se manifestaram e puderam ser desenvolvidas pelos professores participantes, o que sugere que se trata de um espaço potencializador de aprendizagens para o professor e que por isso, precisa ser mais valorizado pelas instâncias formativas.

\section{Referências}

BRASIL. Ministério da Educação e Cultura. Conselho Nacional de Educação. Resolução CNE/CP 1/2002 de 18 de fevereiro de 2002. Institui Diretrizes Curriculares Nacionais para a Formação de Professores da Educação Básica, em nível superior, curso de licenciatura, de graduação plena. Diário Oficial da União, Brasília, 09 abr. 2002.

BRASIL. Ministério da Educação e Cultura. Conselho Nacional de Educação. Resolução CNE/CP 2/2015 de 1 de julho de 2015. Define as Diretrizes Curriculares Nacionais para a Formação inicial em nível superior (curso de licenciatura, cursos de formação pedagógica para graduados e cursos de segunda licenciatura) e para a formação continuada. Diário Oficial da União, Brasília, 2 de julho de 2015.

BRONCKART, Jean Paul. Atividade de linguagem, textos e discursos: por um interacionismo sociodiscursivo. São Paulo: EDUC, 2009 [1999]. 
DOLZ, Joaquim; PASQUIER, A. BRONCKART, Jean-Paul. L'aquisition des discours:emergence d'une competence ou apprentissage de capacities langagiéres? In.: Études de Linguistique Appliquée, 1993, nº92, p. 23-37.

DUBOC, Ana Paula. Letramento crítico nas brechas da sala de línguas estrangeiras. In:TAKAKI, Nara H.; MACIEL, Ruberval F. (Orgs.) Letramentos em terra de Paulo Freire. 2 ed. São Paul o: Ponte, 2015, p. 209-229.

DUDLEY-EVANS, T; ST JOHN, M. Developments in ESP: a multidisciplinary approach. Cambridge: Cambridge University Press, 2005.

FREUDENBERGER, Francieli. $O$ trabalho do professor iniciante de língua estrangeira e as ferramentas docentes: um caminho para compreender o desenvolvimento? 2015 542fl. TeseLinguística, Universidade Federal da Paraíba. João Pessoa, 2015.

HUTCHINSON, T., \& WATERS, A. English for Specific Purposes: A learning-centered approach. Cambridge: Cambridge University Press, 1987.

JEZINE, Edneide. As Práticas Curriculares e a Extensão Universitária. Trabalho apresentado no II Congresso Brasileiro de Extensão Universitária, Belo Horizonte: UFMG, 2004. Disponível em: $\quad$ http://br.monografias.com/trabalhos-pdf901/as-practicas-curriculares/as-practicascurriculares.pdf Acesso em 15 de novembro de 2016.

JORDÃO, Clarissa. Abordagem comunicativa, pedagogia crítica e letramento crítico farinhas do mesmo saco? In: ROCHA, Claudia H.; MACIEL, Ruberval F. (Orgs.). Língua estrangeira e formação cidadã: entre discursos e práticas. Campinas-SP: Pontes, 2013, p.69-90.

MAIA Angélica. A, DOURADO, Maura.R; FERREIRA, Jonathan. F.; CONCEIÇÃO , Cleiton.W. Ensino de língua inglesa e letramento crítico: uma experiência voltada para o engajamento dialógico e cidadão de adolescentes e jovens. Revista Espaço do Currículo (Online), v. 9, p. 97-107, 2016.

MARTINS, Eliecília F. Extensão como componente curricular: oportunidade de formação integral e de solidariedade. Ciências \& Cognição, v.13 (2), p. 201-209, 2008.

MATTOS, Andréa M. A. Educating Language Teachers for Social Justice Teaching. Interfaces Brasil/ Canadá. Canoas, v. 14, n.2, p. 125-151, 2014.

MEDRADO, Betânia. Tornando-se professor: a compreensão de graduandos em Letras sobre a atividade educacional. In: MEDRADO, Betânia P.; REICHMANN, Carla L. (Orgs.). Projetos e práticas na formação de professores de língua inglesa. João Pessoa: Editora da UFPB, 2012, p.151-169.

MEDRADO, Betânia P.; PÉREZ, Mariana (Orgs.) Leituras do agir docente: a atividade educacional à luz da perspectiva interacionista sociodiscursiva. Campinas: Pontes, 2011. 
QUEVEDO-CAMARGO, Gladys. Gênero profissional professor de língua inglesa: qual a base do seu conhecimento? In: CALVO, Luciana C. Simoes; EL KADRI, M.S. ; ORTENZI, Denise Grassano ; SILVA, K. (Orgs.) Reflexões sobre o ensino de línguas e formação de professores no Brasil: uma homenagem a Telma Gimenez. 1. ed. Campinas, SP.: Pontes Editores, 2013, p. 205-227.

. Componentes de um construto para avaliar o (futuro) professor de língua inglesa. In: BEATO-CANATO, Ana Paula M; QUEVEDO-CAMARGO, Gladys. Linguagem e educação: ensino-aprendizagem e formação de professores de línguas - uma homenagem à professora Vera Cristóvão. 1. Ed. Campinas, SP: Pontes Editores, 2015, p.39-70.

REICHMANN, Carla L. A professora regente disse que aprendeu muito: a voz do outro e o trabalho do professor iniciante no estágio. Raído, Dourados, MS, v. 8, n.15, jan./jun, 2014.

ROJO, Roxane. Letramentos múltiplos, escola e inclusão social. São Paulo: Parábola Editorial, 2009.

SCHÖN, Donald. The reflective practitioner. Londres: Temple Smith, 1983.

TARDIF, Maurice. Saberes profissionais dos professores e conhecimentos universitários: Elementos para uma epistemologia da prática profissional dos professores e suas consequências em relação à formação para o magistério. In: Revista Brasileira de Educação. São Paulo, n. 13, 2000, p.5-24. 